period. On completion, subjects were offered to enroll into a follow-up study, where the study physicians were given flexibility to alter VNS dosing parameters and/or to add a biologic disease-modifying antirheumatic drug (DMARD) to the treatment regimen to induce disease remission. Clinical disease activity measures and safety were accessed over 4 years.

Results: All patients electively continued VNS treatment in the long-term follow-up study, 4 subjects withdrew prior to month 48 . Reasons for discontinuation were withdrawal of consent $(\mathrm{N}=3)$ and adverse event due to device discomfort $(\mathrm{N}=1)$. At the start of the follow-up study, the mean DAS28-CRP, CDAI and HAQ-DI were significantly reduced compared to the pre-implant baseline (mean difference $\pm S D$ : DAS28-CRP $=-1.60 \pm 1.13, p<0.001 ; C D A l=-21.19 \pm 13.5, p<0.001 ; \mathrm{HAQ}-\mathrm{Dl}=-0.44 \pm$ $0.49, p<0.01$ ), and this effect was retained through 48 months. Patients using VNS monotherapy and those using a combination of VNS with biologic DMARDs exhibited stable improvements in DAS28-CRP, CDAI and HAQ-DI at month 48 (Table 1). Improvements were observed for patients who both previously had an insufficient response to targeted biological therapies as well those who had an insufficient response to standard DMARDs. No association was seen between DAS28-CRP and stimulation frequency (Range $=1 \mathrm{X}-8 \mathrm{X} /$ day). There was no difference in the adverse events profile between the two groups.

Table 1. Efficacy of VNS treatment.

\begin{tabular}{|c|c|c|c|c|c|c|c|c|c|}
\hline & \multicolumn{3}{|c|}{$\begin{array}{c}\text { Treatment Reinitiated } \\
\qquad \mathrm{N}=9\end{array}$} & \multicolumn{3}{|c|}{$\begin{array}{l}\text { VNS Monotherapy } \\
\qquad \mathrm{N}=8\end{array}$} & \multicolumn{3}{|c|}{$\begin{array}{l}\text { Total } \\
\mathrm{N}=17\end{array}$} \\
\hline & Mo. 24 & Mo. 36 & Mo.48 & Mo. 24 & Mo. 36 & Mo. 48 & Mo. 24 & Mo. 36 & Mo. 48 \\
\hline \multicolumn{10}{|c|}{ Mean change from baseline (SD) } \\
\hline \multirow[t]{2}{*}{ DAS28-CRP } & -2.58 & -2.40 & -2.28 & -2.61 & -1.77 & -2.0 & -2.59 & -2.19 & -2.17 \\
\hline & $(1.0)^{\star \star \star}$ & $(1.0)^{\star *}$ & $(1.3)^{\star *}$ & $(1.3)^{*}$ & $(1.8)$ & (1.7) & $(1.1)^{\star \star \star}$ & $(1.2)^{\star \star}$ & $(1.4)^{\star *}$ \\
\hline \multirow[t]{2}{*}{ CDAI } & -24.06 & -18.02 & -16.2 & -33.5 & -27.8 & -27.9 & -28.20 & -21.93 & -20.83 \\
\hline & $(8.3)^{\star \star \star}$ & * $(13.3)^{*}$ & * (19.6) & $(11.1)^{\star \star *}$ & $(16.0)^{\star}$ & $(12.7)^{\star}$ & $(10.5)^{\star \star \star}$ & $(14.5)^{\star}$ & $(17.5)^{\star}$ \\
\hline \multirow[t]{2}{*}{ HAQ-DI } & -.60 & -.63 & -.31 & -.89 & -.88 & -.88 & -0.73 & -0.73 & -0.54 \\
\hline & $(0.64)^{\star}$ & $(0.45)^{\star}$ & $(0.60)$ & $(0.69)^{\star}$ & $(0.92)$ & $(0.61)$ & $(0.66)^{\star \star \star}$ & $(0.64)^{\star \star}$ & ${ }^{*}(0.64)^{\star}$ \\
\hline
\end{tabular}

${ }^{\star} \mathrm{P}<0.05,{ }^{* \star} \mathrm{P}<0.01,{ }^{* \star *} \mathrm{P}<0.001$ versus primary study baseline (month -3.5 )

Conclusion: VNS was safe, well-tolerated, and resulted in significant and clinically important improvements in disease activity measures that were maintained over 48 months. These results support development of VNS devices as a new therapeutic option for RA treatment.

References:

[1] van Maanen MA, et al. Nat Rev Rheum 2009

[2] Koopman FA, et al. PNAS 2016

[3] Koopman FA, et al. Arthritis Rheum 2018

Disclosure of Interests: Frieda Koopman: None declared, Anne Musters: None declared, Marieke Backer: None declared, Danielle Gerlag Shareholder of: GlaxoSmithKline, Employee of: GlaxoSmithKline, Sanda Miljko: None declared, Simeon Grazio Speakers bureau: Abbvie., Roche, MSD, Eli Lilly, Pfizer, Mylan, Amgen, Fresenius Kabi, Stada, Berlin-Chemie, Sekib Sokolovic: None declared, Yaakov Levine Shareholder of: SetPoint Medical, Employee of: SetPoint Medical, Emmett Glass Employee of: SetPoint Medical, David Chernoff Shareholder of: SetPoint Medical, Adamas Pharmaceuticals, Olly Nutrition, NAIA Pharma, Aquinox Pharma, Consultant of: Adamas Pharmaceuticals, Olly Nutrition, NAIA Pharma, Aquinox Pharma, Crescendo Bioscience, Employee of: SetPoint Medical, Niek de Vries Grant/research support from: AbbVie, Janssen, Ergomed Clinical Research, GlaxoSmithKline, Pfizer, Boehringer Ingelheim, Roche, Consultant of: MSD, Pfizer, Paul P. Tak Shareholder of: GlaxoSmithKline, Employee of: GlaxoSmithKline DOI: 10.1136/annrheumdis-2020-eular.2914

\section{AB1319-HPR EFFECT OF SEGMENTAL STABILIZATION AND PILATES ON CHRONIC NON-SPECIFIC LOW BACK PAIN: PILOT STUDY}

A. Torres $\mathrm{Cruz}^{1}$, P. De Oliveira Januário ${ }^{1}$, I. Coelho Baptista ${ }^{2}$, A. Da Rocha Rodrigues $^{2}$, C. H. Chagas Bernardo ${ }^{2}$, T. Silva Nunes ${ }^{2}$, M. Antunes ${ }^{1}$, I. Merllin Batista de Souza' ${ }^{1}$ A. Pasqual Marques ${ }^{1} .{ }^{1}$ Universidade de São Paulo, Department of Physical Therapy Speech Therapy and Occupational Therapy, São Paulo, Brazil; ${ }^{2}$ Centro Universitário de Barra Mansa, Department of Physical Therapy, Barra Mansa, Brazil

Background: Low back pain is an important health condition with major socioeconomic consequences and is associated with high costs for the health system, absenteeism at work and reduced functional performance. It is one of the most relevant health problems in the elderly, with point prevalence estimates higher than other musculoskeletal conditions.

Objectives: To verify the effect of segmental stabilization versus the Pilates method in the elderly with chronic low back pain.
Methods: The study included 9 elderly women with chronic low back pain randomized into two groups: Segmental Stabilization Group (SG $n=5$; age $65.2 \pm 4.32$ Body Mass Index - BMI $29.99 \pm 4.65$ ) and Pilates Group (PG $n=4$; age $67.75 \pm 7.13$ $\mathrm{BMI} 26.49 \pm 4.06)$. Both groups underwent 16 individual sessions of 60 minutes twice a week and avaliated before and after 8 weeks. Pain was assessed using the Visual Analogue Pain Scale; functional disability, by Oswestry's disability index; excessive fear of movement and physical activity, using the Tampa Kinesiophobia Scale; level of confidence in the balance for specific activities, on the Activity-Specific Balance Confidence $(A B C)$ scale and; activation of the transverse muscle of the abdomen, by the pressure biofeedback unit Stabilizer of the Chatanooga brand. The allocation and evaluations of the participants were performed by a blind examiner. The data were analyzed using the Student's t-test with the level of significance $(p \leq 0.05)$.

Results: The data show significant differences in the reduction of pain intensity $(p=0.022)$ and functional disability $(p=0.023)$ only in SG and improvement in kinesiophobia ( $p=0.007$ ) only in $P G$. The level of confidence in the balance for specific activities was better in the SG when compared to the $P G(p=0.059)$. There was no difference in the activation of the transversus abdominis in both groups.

Conclusion: The results indicate that the segmental stabilization was effective to improve pain and functional disability, Pilates to improve the degree of kinesiophobia and the SG obtained a better result when compared to the PG regarding the level of confidence in the balance for specific activities. Both techniques had a great effect on improving functional capacity and on the level of confidence in the balance for specific activities. It is suggested to carry out studies with a large number of participants and follow-up evaluation to assess the long-term effects. References:

[1] Boonstra AM, Preuper HRS, Reneman MF, Posthumus JB, Stewart RE. Reliability and validity of the visual analogue scale for disability in patients with chronic musculoskeletal pain. IJSR 2008; 3(2):165-9.

[2] Marques AP, Mendes YC, Taddei U, Pereira CAB, Assumpção A. Brazilian-Portuguese translation and cross cultural adaptation of the activities-specific balance confidence ABC) scale. Braz J Phys Ther 2013; 17(2): 170-8.

[3] Siqueira FB, Teixeira-Salmela LF, Magalhães LC. Análise das propriedades psicométricas da versão brasileira da escala tampa de cinesiofobia. Acta Orto Bras 2007; 15(1): 19-24.

[4] Viggato R, Alexandre NMC, Correa Filho HR. Development of a Braziliam Portuguese version of the Oswestry Disability Index: cross-cultural adaptation, reliability, and validity. Spine 2007; 32(4):481-6.

Acknowledgments: Coordenação de Aperfeiçoamento de Pessoal de Nível Superior (CAPES)

Disclosure of Interests: None declared

DOI: 10.1136/annrheumdis-2020-eular.3371

\section{AB1320-HPR THE ASSOCIATION BETWEEN PHYSICAL ACTIVITY AND CARDIORESPIRATORY FITNESS IN PATIENTS WITH RHEUMATOID ARTHRITIS AND HIGH CARDIOVASCULAR RISK}

J. Van den Hoek ${ }^{1}$, M. Van der Leeden², G. Metsios ${ }^{3}$, G. Kitas ${ }^{4}$, H. Jorstad ${ }^{2}$, W. Lems ${ }^{2}$, M. Nurmohamed ${ }^{2}$, M. Van der Esch ${ }^{5} .{ }^{1}$ Amsterdam Rehabilitation Research Center| Reade, Amsterdam, Netherlands; ${ }^{2}$ Amsterdam University Medical Centers, Amsterdam, Netherlands; ${ }^{3}$ University of Wolverhampton, West Midlands, United Kingdom; ${ }^{4}$ Russel's Hall Hospital, West Midlands, United Kingdom; ${ }^{5}$ Amsterdam Rehabilitation Research Center | Reade, Amsterdam, Netherlands

Background: Rheumatoid arthritis (RA) is associated with increased risk of cardiovascular disease (CVD) disease and CV mortality ${ }^{1}$. High values of cardiorespiratory fitness (CRF) are protective against CVD and CV mortality ${ }^{2}$. Physical activity levels in patients with RA are low. Knowledge on whether physical activity is associated with CRF in patients with RA and high CV risk is scarce. This knowledge is important because improving the level of physical activity could improve CRF and lower CV risk in this group of patients with RA and high CV risk. However, it is unclear whether physical activity is associated with CRF in this group of patients. This study presents the preliminary results at baseline of the association of physical activity with CRF from an ongoing pilot study aimed at improving CRF through exercise therapy in patients with RA and high CV risk. Objectives: To determine (i) the level of physical activity in patients with RA and high CV risk and (ii) whether physical activity is associated with CRF in patients with RA and high $\mathrm{CV}$ risk.

Methods: Patients with RA and high CV risk participated in this pilot study. Increased 10-year risk of CV mortality was determined by using the Dutch SCORE-table. Anthropometrics and disease characteristics were collected. Physical activity was assessed with an Actigraph accelerometer to determine the number of steps and intensity of physical activity expressed in terms of sedentary, light, and moderate-to-vigorous time per day. Participants wore the acceler ometer for seven days. A minimum of four measurement days with a wear time of 